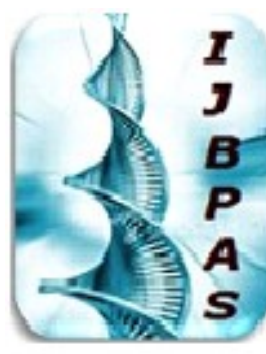

International Journal of Biology, Pharmacy and Allied Seiences (IJBPAS)

'A B Bridge Between Caboratory and QRader'

Www.iibpas,com

\title{
DEVELOPMENT AND EVALUATION OF TRANSDERMAL DRUG DELIVERY SYSTEM OF FIXED-DOSE COMBINATION DRUGS OF DIABETES
}

\section{MISHRA A ${ }^{1 *}$, KARVE $M^{1}$ AND PATEL $S^{2}$}

1: Department of Industrial Chemistry, Institute of Science and Technology for Advanced Studies and Research (ISTAR), Vallabh Vidyanagar 388 120, India

2: Department of Pharmaceutical Chemistry, Ashok \& Rita Patel Institute of Integrated Study and Research in Biotechnology and Allied Sciences (ARIBAS), New Vallabh Vidyanagar 388 121, India

*Corresponding Author: E-Mail: arun4th@yahoo.com

Received 27 $7^{\text {th }}$ Jan. 2020; Revised 26 ${ }^{\text {th }}$ Feb. 2020; Accepted $4^{\text {th }}$ April 2020; Available online $1^{\text {st }}$ Sept. 2020

\section{https://doi.org/10.31032/IJBPAS/2020/9.9.5193}

\section{ABSTRACT}

Diabetes is a disorder which requires continuous use of drugs for its maintenance and this disease is characterized by defective insulin secretion and increased insulin resistance. Metformin has a plasma elimination half-life of 3 hours and Glimepiride has 5 hours; therefore, transdermal combination sustained release dosage form was developed by using different plasticizer like Cellulose acetate butyrate $(\mathrm{CAB})$ and Cellulose acetate propionate (CAP), Ethyl cellulose (EC), Dibutyl phthalate (DBP), Dichloromethane (DCM) and Dimethylsulfoxide as penetration enhancer. In vitro studies of all the patches showed expected release for $14 \mathrm{hrs}$ for releasing glimepiride and metformin single dose at faster rate. Among all patches F4 had faster release of 99 98\% within 14 hrs. Kinetics of drug release also were showings that F4 formulation that contains combination of polymers $\mathbf{E C}+\mathbf{C A B}$ follows the Higuchi model which shows the controlled release of drug and confirmed by the Korsmeyer-peppas model of kinetic release. F3 follow the zero order kinetic that implies the drug level in the blood remains constant throughout the delivery.

Key words: Metformin Hydrochloride, Glimepiride, Higuchi model, Korsmeyer-peppas model, kinetic model, IR

\section{INTRODUCTION}

Diabetes is a disorder which requires defective insulin secretion and increased continuous use of drugs for its maintenance and this disease is characterized by insulin resistance [1]. Metformin Hydrochloride, Glimepiride, Biguanide, are 
the examples of orally active antidiabetic agent and their mode of action is to increase the secretion of insulin or reduce insulin resistance or increase glucagon [1, 2]. Sometimes, monotherapy is not effective as it is evidenced in failure of blood glucose control overtime, however combination therapy using sulfonylurea and metformin is advisable which promotes insulin secretion and improves insulin resistance [3, 4]. Therefore, it seems advisable to use combination therapy with a complementary mechanism rather than increasing to the maximal dose in type 2 diabetes patients inadequately controlled by monotherapy [5].Considering the compliance and cost-effectiveness, the use of a fixed-dose combination pill of sulfonylurea and metformin has recently increased with the expectation of minimum side-effect [6].

Metformin has a plasma elimination halflife of 3 hours and Glimepiride has 5 hours; therefore, it is suitable candidate for development of a combination sustained release dosage form.

Several attempts have been made to develop transdermal systems to avoid the flaws of conventional drug delivery of antidiabetic drugs [7, 8]. The major drawback of transdermal delivery of drugs is the resistance in permeation created by skin. For the effective permeation of drugs through the skin, various penetration enhancers are tried in the formulations [9, 10].

The purpose of the present study was to develop and identify the best possible formulation with effective bioavailability of Metformin and Glimepiride as combination therapy through transdermal route.

\section{MATERIALS AND METHOD}

Metformin and Glimepiride was obtained as a gifted by Zydus Cadilla, Ahemedabad. Celluloseacetatebutyrate (CAB) and Celluloseacetatepropionate (CAP) were purchased from Aldrich USA. Ethylcellulose (EC) was obtained from HiMedia Laboratories Pvt. Ltd. Dibutylphthalate (DBP), Dichloromethane (DCM), penetration enhancer dimethylsulfoxide and Chloroform were obtained from Loba Chemicals Pvt. Limited Mumbai (Maharashtra). All the reagents used for this study were of analytical grade.

\section{Preparation of blank patch:}

Transdermal place bofilms were prepared by solvent evaporation method. Differentpolymers (EC, CAB. CAP, $\mathrm{EC}+\mathrm{CAB}$ ) were weighed insuitable concentration and dissolved in appropriate solvent. Add plasticizer in $\mathrm{w} / \mathrm{v}$ of polymer centration. Solutions were stirred on magnetic stirrer. Then solutions were poured in petridish and dried at R. M. for 
24 hrs.

The drug loaded patches of Metformin and Glimepiride were prepared by solvent evaporation method. Accurately weighed quantity of polymers ethylcellulose, celluloseacetatebutyrate, and combination of ethylcellulose and cellulose-acetatebutyrate in suitable concentration get dissolved in dichloromethane solvent. Also cellulose acetate propionate weighed and dissolved it in chloroform. Dibutylpthalate (plasticizer) was added in $\mathrm{w} / \mathrm{v}$ of polymer concentration. Solutions were mixed on magnetic stirrer for $24 \mathrm{hrs}$ at room temperature. Accurately $10 \mathrm{mg}$ of Glimepiride drug was added and stirred the solutions for $30 \mathrm{mins}$ on magnetic stirred. Then it was poured in a petridish for evaporation by putting inverted funnel for control evaporation. After $24 \mathrm{hrs}$ film formation was noted by observing surface after complete evaporation. And then patch were removed. The composition of transdermal patches is shown in Table 1.

Table1: Composition of transdermal patches

\begin{tabular}{|c|c|c|c|c|c|c|}
\hline Sr. No. & $\begin{array}{c}\text { Formulation } \\
\text { code }\end{array}$ & Polymers & Concentration & Solvent & Plasticizer & $\begin{array}{c}\text { Drug } \\
\text { Metformin and } \\
\text { Glimepiride }\end{array}$ \\
\hline 1 & FI & EC & 0.5 & DCM & $32 \%$ & $10 \mathrm{mg}$ \\
\hline 2 & F2 & CAP & 0.5 & Chloroform & $30 \%$ & $10 \mathrm{mg}$ \\
\hline 3 & F3 & CAB & 0.3 & DCM & $20 \%$ & $10 \mathrm{mg}$ \\
\hline 4 & F4 & EC+CAB & $\mathbf{0 . 4}$ & DCM & $30 \%$ & $10 \mathrm{mg}$ \\
\hline
\end{tabular}

In vitro drug release study [10]:

This study carried out by Franz diffusion cell with receptor compartment capacity of $50 \mathrm{ml}$. Dialysis membrane was mounted between donor compartment and receptor compartment of diffusion cell. Formulated drug loaded patches were cut in $1 \mathrm{~cm}^{2}$ and placed over the dialysis membrane. Receptor compartment was filled with phosphate buffer $\mathrm{pH}$ 7.4. Whole assembly fixed on magnetic stirrer was stirred using magnetic bead at 50rpm. Temperature was maintained at $37 \mathrm{C}$. $5 \mathrm{ml}$ of sample was withdrawn at regular interval of $30 \mathrm{~min}$ for 9hrs. Same volume of phosphate buffer was replaced to maintain cell condition. The amount of drug release was determined by measuring the absorbance of samples at $230 \mathrm{~nm}$.

\section{Application of drug released at a on mathematical models:}

Several mathematical equations which generally define the dissolution profile were applied to determine the drug release profile and correlate with drug release kinetic models. The applied mathematical models are explained below.

\section{Zero order model [11, 12]:}

Zero order kinetics defines the process of constant drug release from a drug delivery system and drug level in the blood remains constant throughout the delivery. Hence to study the drug release kinetics data obtained from in-vitro dissolution study is 
plotted against time i.e., cumulative drug release vs. time.

First order model [11, 13]: In the first order process rate is directly proportional to the concentration of drug undergoing reaction i.e., greater the concentration faster the reaction. Hence, it follows linear kinetics. and to study the drug release kinetics data obtained from in-vitro dissolution study is plotted against time i.e., $\log \%$ of drug remaining vs. time and the slope of the plot gives the first order rate constant.

Higuchi model [13]: The release of a drug from a drug delivery system (DDS) includes both diffusion and dissolution. The Higuchi equation is widely considered for controlled-release equation.

The data obtained were plotted as cumulative percentage drug release versus square root of time. The higher correlation coefficient illustrates the prime mechanism of drug release is diffusion controlled release mechanism.

Hixson-crowell model [14]: The HixsonCrowell cube root law describes the release from systems where there is a change in surface area. Hence, particles of regular area are proportional to the cube root of its volume. From the above concept HixsonCrowell established a relationship between drug release and time.

To study the release kinetics a graph is plotted between cube root of drug percentage remaining in matrix versus time. Higher correlation coefficient interprets the significant effect on drug release with change in surface area during the process of dissolution.

\section{Korsmeyer-peppas model [14]:}

Korsmeyer and Peppas described the drug release from a polymeric system. To study release kinetics a graph is plotted between $\log$ cummulative \% drug release vs. $\log$ time $(\log t)$.

\section{RESULT AND DISCUSSION}

\section{Physicochemical Characteristics}

The results are given in Table 2

\section{Thickness}

Table 2 shows the thickness of patch which was measured at five different points using micrometer screwgauze and the average thickness was calculated, and found 0.31 to $0.22 \mathrm{~mm}$ with maximum variation of $0.012-0.032 \mathrm{~mm}$

\section{Tensile strength:}

The tensile strength of the patches was found to vary with the amount of plasticizer used during formulating patches [15]. As shown in Table 2 the patches of EC demonstrated maximum tensile strength of $3.77 \mathrm{~kg} / \mathrm{cm}$ while the patch of its combination with $\mathrm{CAB}$ showed least tensile strength of $1.796 \mathrm{~kg} / \mathrm{cm}$ whereas other two patches of $\mathrm{CAB}$ and $\mathrm{CAP}$ showed average $2 \mathrm{~kg} / \mathrm{cm}^{2}$.

\section{Folding endurance:}


Folding endurance is to measure the capacity of sample to withstand folding pressure which indicates brittleness; less folding endurance indicates more brittleness [15]. This study is carried out by repeatedly folding the patch at the same place until it breaks. From the Table 2 it can be concluded that the folding endurance is $\mathrm{CAP}>\mathrm{EC}+\mathrm{CAB}>\mathrm{CAB}>\mathrm{EC}$.

\section{Flatness:}

A transdermal film should in hold even surface and should not narrow down with time. In this work flatness study represented zero constriction which determined by cutting one strip from the center or and two from either end of the patch the length of each strip was measured and difference in length was calculated. All patches gave $0 \%$ constriction means all patches have $100 \%$ flat.

\section{Weight uniformity:}

Five different patches of the individual batch were weighed on electrical weighing balance and the average was calculated. The films demonstrated homogenous weight ranging from 0.31 to 0 . : $>4 \mathrm{~g}$ with least variation in values.

\section{Drug content:}

The drug content for all the formulations was calculated by extracting the drug from accurately weighed patch. For the different formulations drug content was known to vary between $95 \%$ to $98 \%$. The cumulative percentage drug permeated and percentage drug pertained by each patch. In vitro skin permeation studies were relying on the drug present in the individual patch. Drug distribution was found to be consistent in the polymeric films.

\section{Swell ability:}

All the patches were subjected to check the swell ability by immersing the patches in distilled water and at regular time intervals their weight was measured by digital weighing balance. It was observed that among all patches, the combination of ethylcellulose and $\mathrm{CAB}$ was having 50\% swellability while CAP showed least ability with $11.16 \%$. The rest formulated patches of $\mathrm{EC}$ and $\mathrm{CAB}$ demonstrated average swellability of $31.25 \%$ and $19 \%$ respectively which indicates that these patches can be further utilized for study of transdermal delivery of drug.

\section{Physical appearance:}

The formulated transdermal patches were white, smooth, uniform, flexible and transparent. The method applied for preparation of patch system was found satisfactory.

\section{Drug polymer interaction study}

The IR spectra of the compounds are show in Figure 1 to 8 and major peaks obtained are described in Table 3.

From the Table 3 and Figure 1 to 8 it can be concluded that the formulated 
transdermal patch F1, F2, F3 and F4 show major peaks which differs from the individual spectra of drug and polymer. These results showed that there was no interaction between drugs, solvent and polymers.

\section{Diffusion study:}

Keshary Che in diffusion cell was used to study the diffusion for different patches F1F4. The transdermal patches F1-F4 were observed for diffusion study for $14 \mathrm{hrs}$. The drug released of every Patches are shown in

Table 3.

In vitro Drug release profile of different patches

Various mathematical models are employed to understand drug release kinetics which is explained below in Table 4, 5 .

\section{Zero order model}

Observation: The graphical representation of cumulative $\%$ of drug release against time describes that drug release of formulation F1, F2 and F4 does not follow perfectly the principle of zero order release kinetics. However, formulation F3 follows the Zero order kinetics (Figure 9).

Observation: The graphical representation of cumulative $\%$ of drug release against time describes that drug release of Drugs from the patches does not follow the principle of first order release kinetics (Figure 10).

Observation: Formulation F4 follows the Korsmeyer-peppas model of kinetics (r2 = 0.9902) (Figure 11).

Observation: Formulation F4 is following Higuchi drug release model as the drug release profile is very closest to trend line or regression line and there is highest value of coefficient of correlation $\left(r^{2}=0.9965\right)$ (Figure 12).

Observation: From the above figures it was predicted that change in surface area and diameter of the tablets with the progressive dissolution of matrix is not the function of time [16] (Figure 13).

\begin{tabular}{|c|c|c|c|c|c|c|c|c|c|}
\hline Sr. No. & Polymer & Thickness (pm) & $\begin{array}{c}\text { Tensile } \\
\text { strength }\end{array}$ & $\begin{array}{c}\text { Folding } \\
\text { endurance }\end{array}$ & Flatness & $\begin{array}{c}\text { Weight } \\
\text { uniformity(g) }\end{array}$ & $\begin{array}{c}\text { Drug } \\
\text { content }\end{array}$ & $\begin{array}{c}\text { Swell } \\
\text { ability }\end{array}$ & $\begin{array}{c}\text { Physical } \\
\text { appearance }\end{array}$ \\
\hline 1 & F1 & $0.31 \pm 0.01$ & 3.77 & $<20$ & $100 \%$ & $0.51 \pm 0.12$ & $95 \%$ & $31.25 \%$ & Translucent \\
\hline 2 & F2 & $0.28 \pm 0.03$ & 2.82 & 140 & $100 \%$ & $0.54 \pm .081$ & $95 \%$ & $11.16 \%$ & Transparent \\
\hline 3 & F3 & $0.20 \pm 0.01$ & 2.0 & 70 & $100 \%$ & $0.31 \pm .016$ & $97 \%$ & $19 \%$ & Transparent \\
\hline 4 & F4 & $0.22 \pm 0.02$ & 79 & 110 & $100 \%$ & $0.42 \pm .0081$ & $98 \%$ & $50 \%$ & Transparent \\
\hline
\end{tabular}

Table 3: Major peaks of IR spectra of drugs, polymers and formulations

\begin{tabular}{|c|c|}
\hline Compound & Major Peaks \\
\hline Glimeperide & $3444,2929,1708.1347 \mathrm{~cm}^{-1}$ \\
\hline Metformin & $3372,2816,1583,1170 \mathrm{~cm}^{-1}$ \\
\hline Ec Polymer & $3453,2977,2872,1632,1110 \mathrm{~cm}^{-1}$ \\
\hline CAP & $3459,2976,2879,1752,1407 \mathrm{~cm}^{-1}$ \\
\hline CAB & $3451,2967,2936,1383,1047 \mathrm{~cm}^{-1}$ \\
\hline F1 & $3455,2973,2930,1792,1119 \mathrm{~cm}^{-1}$ \\
\hline F2 & $3440,2926,2876,1744,1053 \mathrm{~cm}^{-1}$ \\
\hline F3 & $3441,2926,2854,1633,1053 \mathrm{~cm}^{-1}$ \\
\hline F4 & $3441,2925,2854,1632,1072 \mathrm{~cm}^{-1}$ \\
\hline
\end{tabular}



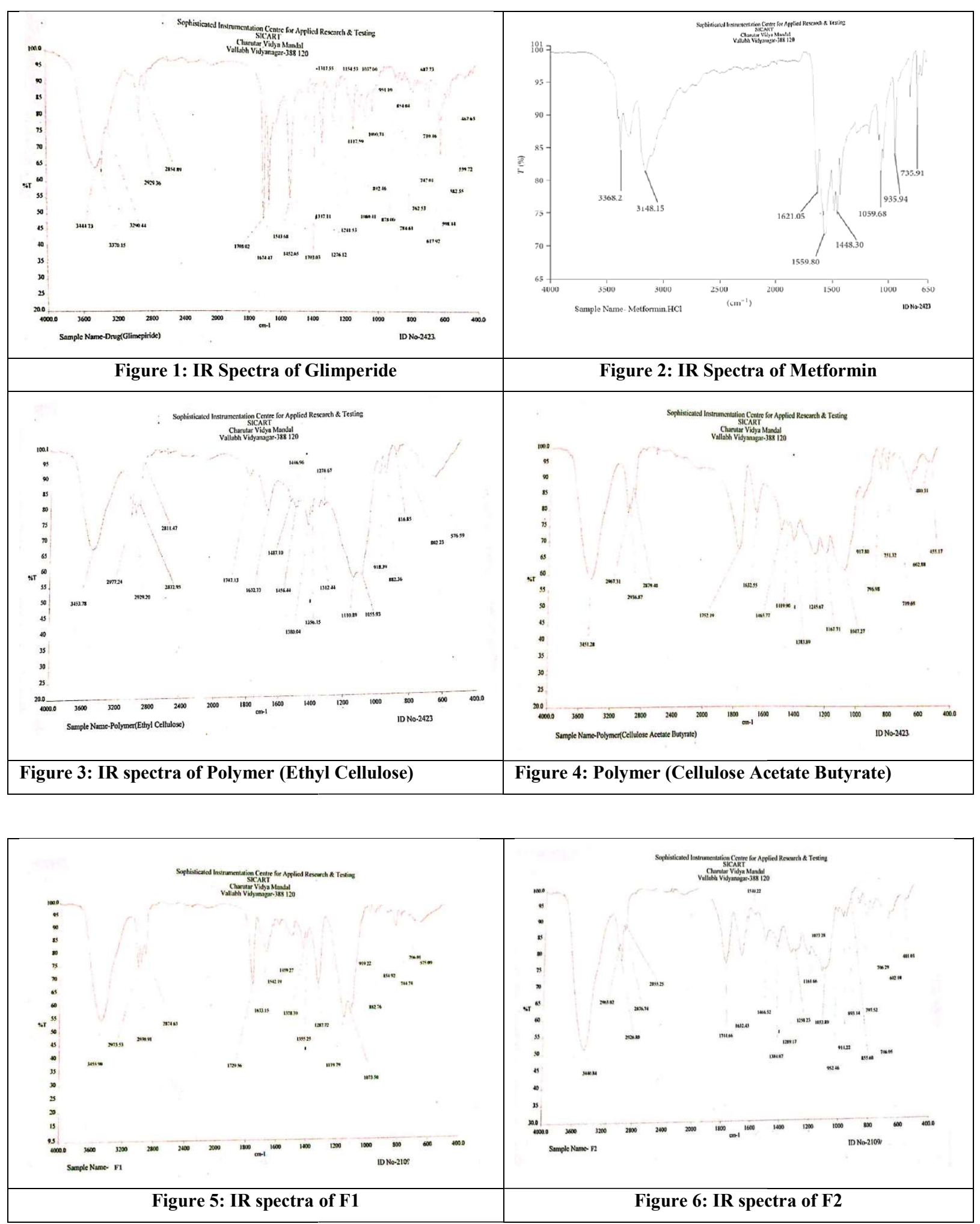


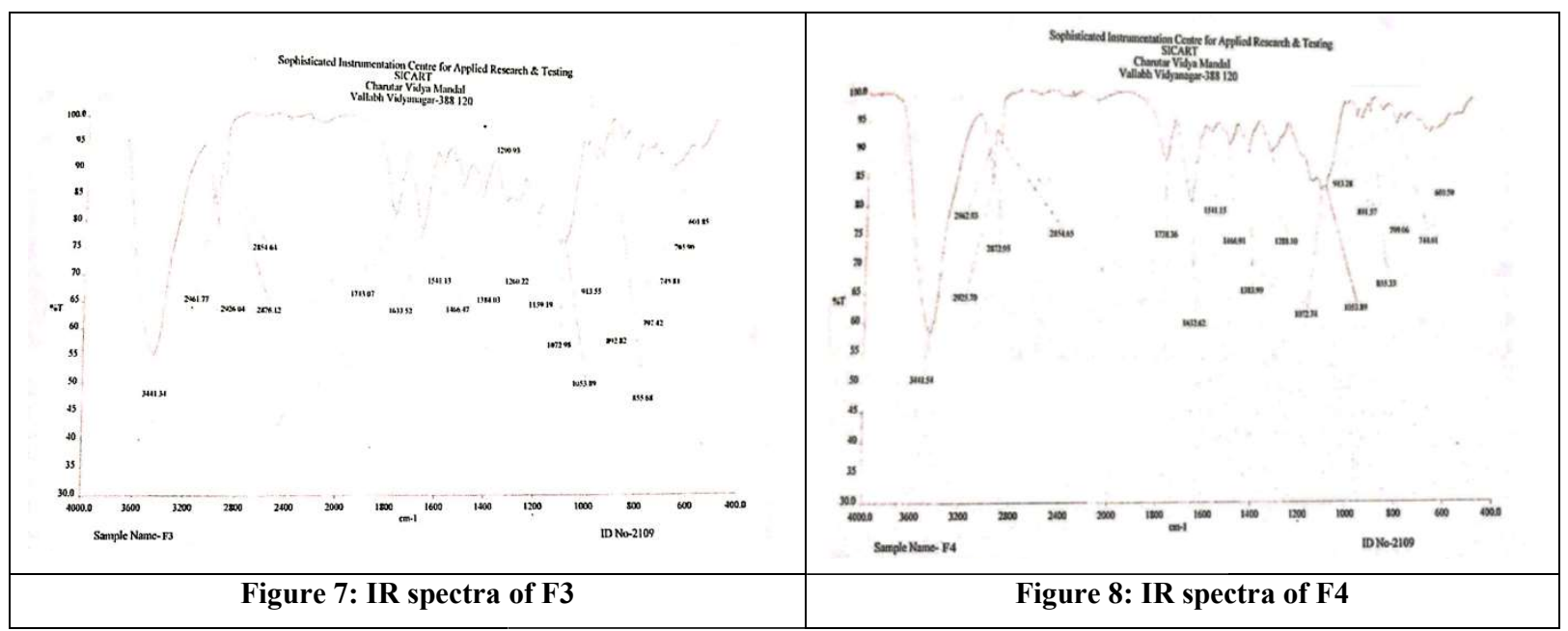

Table 4: Cumulative \% Drug Diffusion

\begin{tabular}{|c|c|c|c|c|c|}
\hline Sr. No. & TIME & FI & F2 & F3 & F4 \\
\hline 1 & $\mathbf{0}$ & $\mathbf{0}$ & $\mathbf{0}$ & $\mathbf{0}$ & $\mathbf{0 1}$ \\
\hline 2 & 2 & $\mathbf{2 7 . 9 4 5}$ & $\mathbf{3 3 . 3 4 5}$ & $\mathbf{2 1 . 1 9 5}$ & $\mathbf{3 7 . 3 9 5}$ \\
\hline 3 & 4 & $\mathbf{3 9 . 3 0 5 2 5}$ & $\mathbf{4 4 . 3 0 0 2 5}$ & $\mathbf{3 3 . 4 6 2 7 5}$ & $\mathbf{4 8 . 4 0 2 7 5}$ \\
\hline 4 & $\mathbf{6}$ & 49.7625 & $\mathbf{5 6 . 5 4 0 2 5}$ & $\mathbf{4 1 . 6 3 . 2 5}$ & $\mathbf{6 4 . 6 6 2 7 5}$ \\
\hline 5 & $\mathbf{8}$ & $\mathbf{6 6 . 0 2 0 2 5}$ & $\mathbf{6 6 . 0 5 7 7 5}$ & $\mathbf{5 8 . 8 2 0 2 5}$ & $\mathbf{7 6 . 9 0 2 7 5}$ \\
\hline 6 & 10 & $\mathbf{7 5 . 5 6 0 2 5}$ & $\mathbf{7 2 . 7 2 5 2 5}$ & $\mathbf{7 8 . 6 2 5 5}$ & $\mathbf{8 2 . 3 7 0 2 5}$ \\
\hline 7 & 12 & $\mathbf{8 2 . 3 6 2 7 5}$ & $\mathbf{8 9 . 1 1 2 7 5}$ & $\mathbf{8 6 . 5 6 5}$ & $\mathbf{9 0 . 5 0 0 2 5}$ \\
\hline 8 & 14 & $\mathbf{9 7 . 2 5 0 2 5}$ & $\mathbf{9 9 . 4 5 5 2 5}$ & $\mathbf{9 8 . 4 8 8 5}$ & $\mathbf{9 9 . 9 8 7 7 5}$ \\
\hline
\end{tabular}

Table 5: In vitro dissolution kinetics

\begin{tabular}{|c|c|c|c|c|c|c|}
\hline S.No. & Formulation & \multicolumn{5}{|c|}{ Value of $\mathbf{R}^{2}$} \\
\hline & & Zero order & First order & $\begin{array}{c}\text { Higuchi } \\
\text { Model }\end{array}$ & Peppas Model & $\begin{array}{c}\text { Hixson } \\
\text { Crowel }\end{array}$ \\
\hline 1. & F1 & $\mathbf{0 . 9 7 2 9}$ & $\mathbf{0 . 9 7}$ & $\mathbf{0 . 9 7 4 7}$ & $\mathbf{0 . 9 8 7 8}$ & $\mathbf{0 . 6 7 8}$ \\
\hline 2. & F2 & $\mathbf{0 . 9 5 5 6}$ & $\mathbf{0 . 7 5 8 1}$ & $\mathbf{0 . 9 8 2}$ & $\mathbf{0 . 9 8 1 3}$ & $\mathbf{0 . 6 4 2 4}$ \\
\hline 3. & F3 & $\mathbf{0 . 9 9 0 1}$ & $\mathbf{0 . 7 9 0 7}$ & $\mathbf{0 . 9 3 0 5}$ & $\mathbf{0 . 9 8 1 3}$ & $\mathbf{0 . 7 5 0 1}$ \\
\hline 4. & F4 & $\mathbf{0 . 9 2 1 1}$ & $\mathbf{0 . 8 3 4 6}$ & $\mathbf{0 . 9 9 6 5}$ & $\mathbf{0 . 9 9 0 2}$ & $\mathbf{0 . 6 1 0 1}$ \\
\hline
\end{tabular}

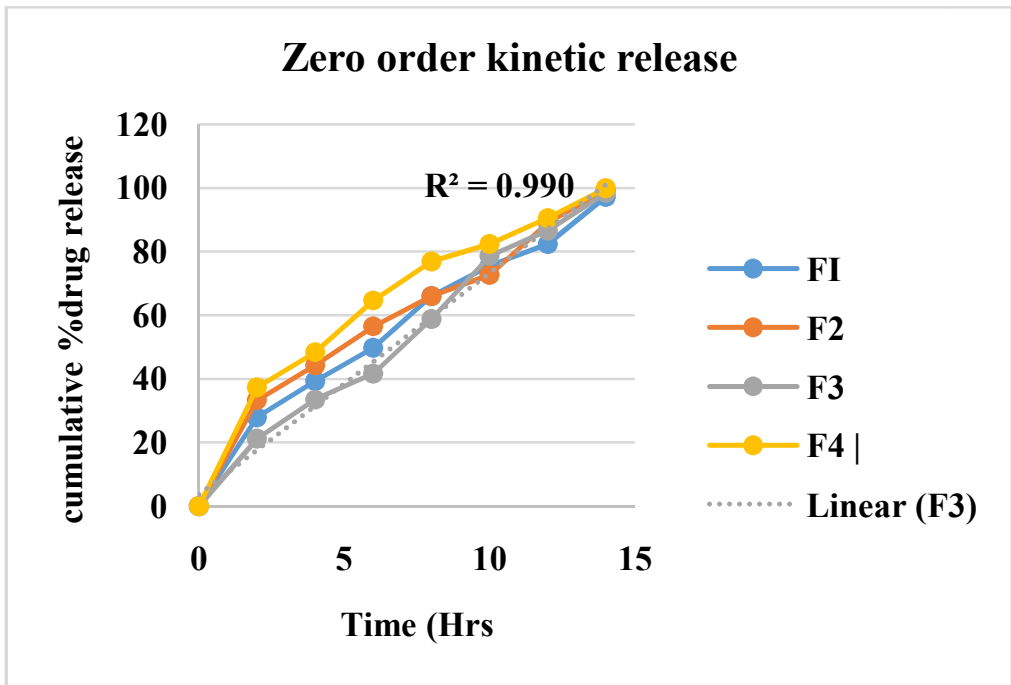

Figure 9: Zero order kinetic release 


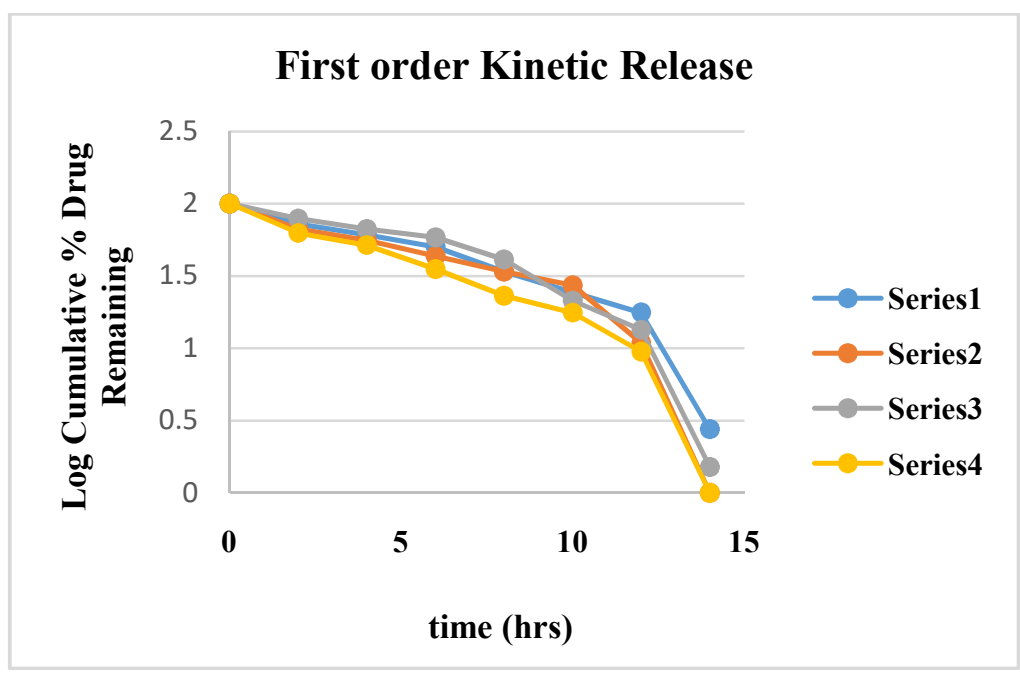

Figure 10: First order kinetic release

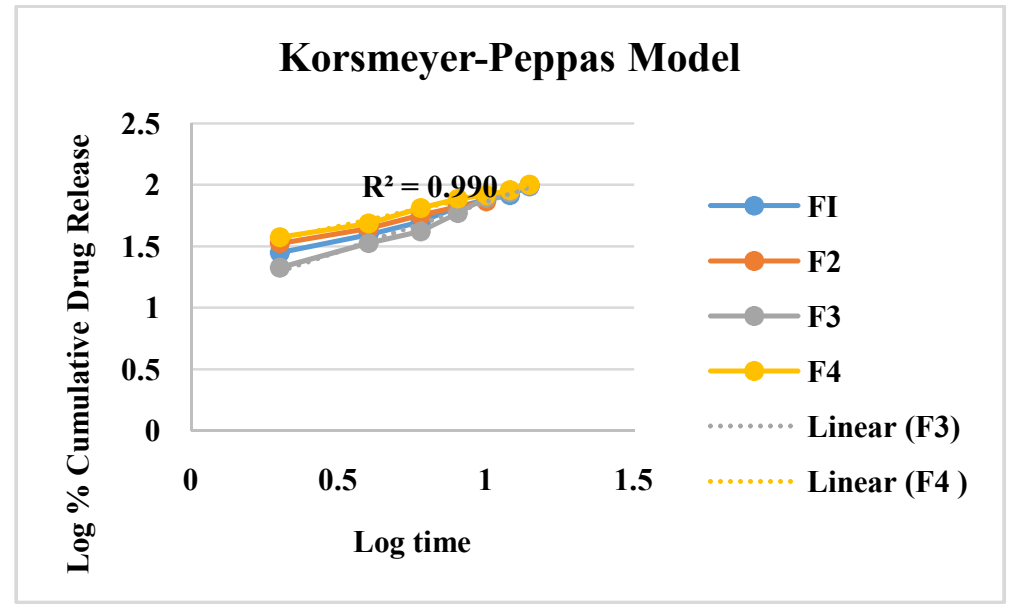

Figure 11: Korsmeyer-peppas model of kinetic release

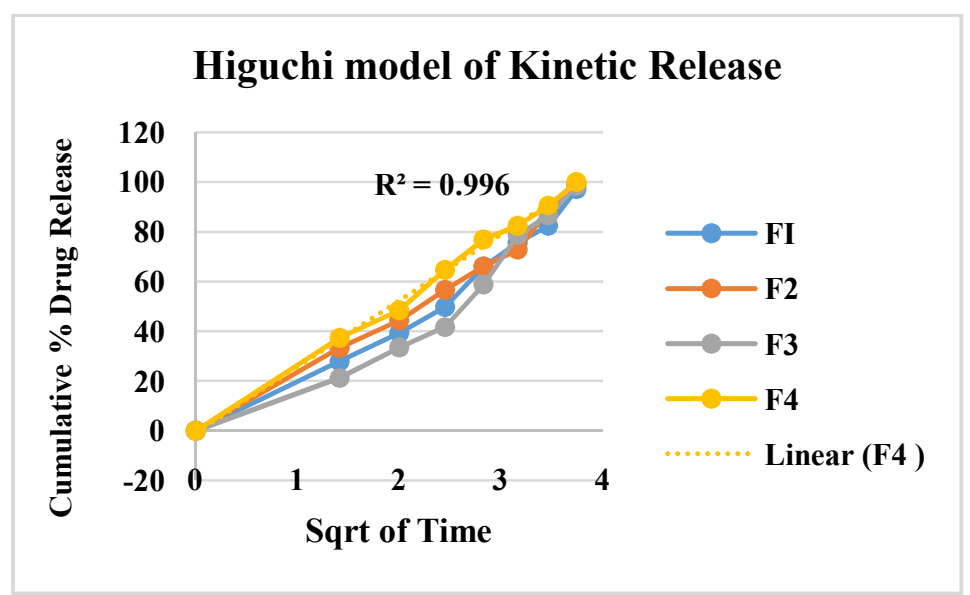

Figure 12: Higuchi model of Kinetic Release 


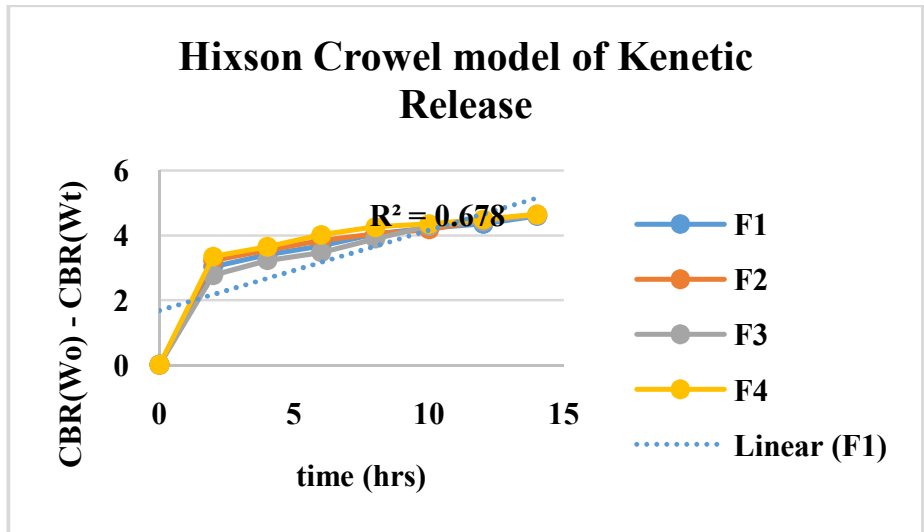

\section{CONCLUSION}

By compatibility study FT-1 R of drug-polymer gave confirmation about their purity and no interaction between drug and the polymers. All the formulated transdermal patches were showing required physicochemical properties such as thickness, weight uniformity, drug content, folding endurance etc.

From the designed patches it was observed that the patches prepared by using dibutylphalate plasticizer has high folding endurance values while the rest has comparatively lower folding endurance and indicating less brittleness.

The results of drug content study represented that the drug was distributed properly in every patches and the standard deviation were within agree able limits.

Invitro studies of all the patches showed expected release for $14 \mathrm{hrs}$ for releasing glimepiride and metformin single dose at faster rate and the time period consumed for the release of drug was considered appropriate for all the patches. Among all patches F4 had faster release of $9998 \%$ within $14 \mathrm{hrs}$.

Kinetics of drug release also shows that F4 formulation that contains combination of polymers $\mathbf{E C}+\mathbf{C A B}$ following the Higuchi model which shows the controlled release of drug and confirmed by the Korsmeyer-peppas model of kinetic release. F3 follow the zero order kinetic that implies the drug level in the blood remains constant throughout the delivery.

\section{Acknowledgements}

We are heartily thankful to Charutar Vidya Mandal Vallabh Vidyanagar and SICART for providing us facilities to carry out our research work successful.

\section{REFERENCES}

[1] Bhupendra Prajapati, Rakesh Patel, Dhaval Patel, Payal Shah e-Journal of Science \& Technology (e-JST) (4), 8, 2013 61-72]

[2] Turner RC, Cull CA, Frighi V, et al. Glycemic control with diet, sulfonylurea, metformin, or insulin in patients with type 2 diabetes mellitus: progressive requirement for multiple therapies (UKPDS 49). UK Prospective Diabetes Study (UKPDS) Group. JAMA. 1999; 281: 2005-2012.

[3] Hermann LS, Scherstén B, Bitzén PO, et al. Therapeutic comparison of metformin and sulfonylurea, alone and in various combinations. A doubleblind controlled study. Diabetes Care. 1994; 17: 1100-1109. 
[4] U.K. Prospective Diabetes Study Group. UKPDS 28: a randomized trial of efficacy of early addition of metformin in sulfonylurea-treated type 2 diabetes. Diabetes Care. 1998; 21: 87-92.

[5] Yoon KH, Shin JA, Kwon HS, et al. Comparison of the efficacy of glimepiride, metformin, and rosiglitazone monotherapy in Korean drug-naïve type 2 diabetic patients: the practical evidence of antidiabetic monotherapy study. Diabetes Metab J. 2011; 35: 26-33.

[6] Melikian C, White TJ, Vanderplas A, et al. Adherence to oral antidiabetic therapy in a managed care organization: a comparison of monotherapy, combination therapy, and fixed-dose combination therapy. Clin Ther. 2002; 24: 460-467.

[7] Ahad A, Al-Saleh AA, Akhtar N, AlMohizea AM, Al-Jenoobi FI. Transdermal delivery of antidiabetic drugs: formulation and delivery strategies. Drug Discov Today. 2015; 20(10): 1217-1227.

[8] Arry BW. Penetration enhancer classification. In: Smith E, Maibach HI, editors. Percutaneous Penetration Enhancers. 2nd ed. CRC Press; 1996. pp. 3-15.

[9] Alexander A, Dwivedi S, Giri TK, Saraf S, Saraf S, Tripathi DK. Approaches for breaking the barriers of drug permeation through transdermal drug delivery. J Control Release. 2012; 164(1): 26-40.

[10] Williams AC, Barry BW. Terpenes and the lipid-protein-partitioning theory of skin penetration enhancement. Pharm Res. 1991; 8(1): $17-24$.

[11] Gouda R, Baishya H, Qing Z (2017) Application of Mathematical Models in Drug Release Kinetics of Carbidopa and Levodopa ER Tablets. J Develop Drugs 6: 171

[12] Dash S, Murthy PN, Nath L, Chowdhury P (2010) Kinetic modeling on drug release from controlled drug delivery systems. Acta Pol Pharm 67: 217-223.

[13] Subal CB (2006) Modelling of Drug release: The Higuchi equation and its application. Pharmabiz.com.

[14] Singhvi G, Singh M (2011) In-vitro drug release characterization models. Int J Pharm Stud Res 2: 77-84.

[15] Akram MR, Ahmad M, Abrar A, Sarfraz RM, Mahmood A. Formulation design and development of matrix diffusion controlled transdermal drug delivery of glimepiride. Drug Des Devel Ther. 2018; 12: 349-364

[16] Banker GS, Siepmann J, Rhodes C (2002) Modern pharmaceutics. CRC Press, Florida, USA. 